\title{
The Simple Dynamics of 'Animal Spirits'
}

by Elliott Middleton, Ph.D.

elliott.middletoniii@gmail.com

25 March 2020

Twenty-four years ago, I published an article in the Journal of Economic Psychology, titled "Adaptation Level and 'Animal Spirits'" [1]. The revolutionary insight of this article, which was far too practical, realistic, and "Marxist" for mainstream economics, was that in America's capital-controlled labor markets, where virtually everyone's employment relationship is tenuous, people play close attention to the published unemployment rate, and use it as a gauge of their own likelihood of losing their own job.

\begin{abstract}
In the tradition of physiological psychology dating back to Wilhelm Wundt, an adaptation-level approach is taken to the level of economic certainty, as measured by the psychologically sensitive unemployment series. Unemployment levels 'low' relative to the adaptation level are shown to promote confidence — high 'animal spirits' — while the converse holds for 'high' unemployment rates. [...] It is suggested that attempts to smooth the business cycle may become counterproductive (to the extent that such policy can be considered exogenous) if they produce less than 'optimal' levels of 'variety', construed in this context as alternation of confidence levels. [...]
\end{abstract}

The sensitivity to adaptation level is arguably the oldest law of psychology, often attributed to Max Wilhelm Wundt in 1876. For example, if you lift a 50 pound barbell first, and then a 25 pound barbell, the latter will seem light. If you stick your left hand in a bowl of ice water, and your right hand in a bowl of hot water, and then put them both in a bowl of tepid water, the tepid water will seem hot to your left hand and cold to your right. We are sensitive to adaptation level in virtually every possible way, perceptually and cognitively. The sensitivity to adaptation level is implicitly widely acknowledged in financial markets, where it has led to the development of many moving average trading rules.

The adaptation level for unemployment that I calculated in 1996 and have used since then is an exponentially weighted moving average over the previous 48 months. The figure below shows the actual unemployment rate and the adaptation level since 1953. I assumed the March 2020 unemployment number will be 6.5 percent just for illustrative purposes. 


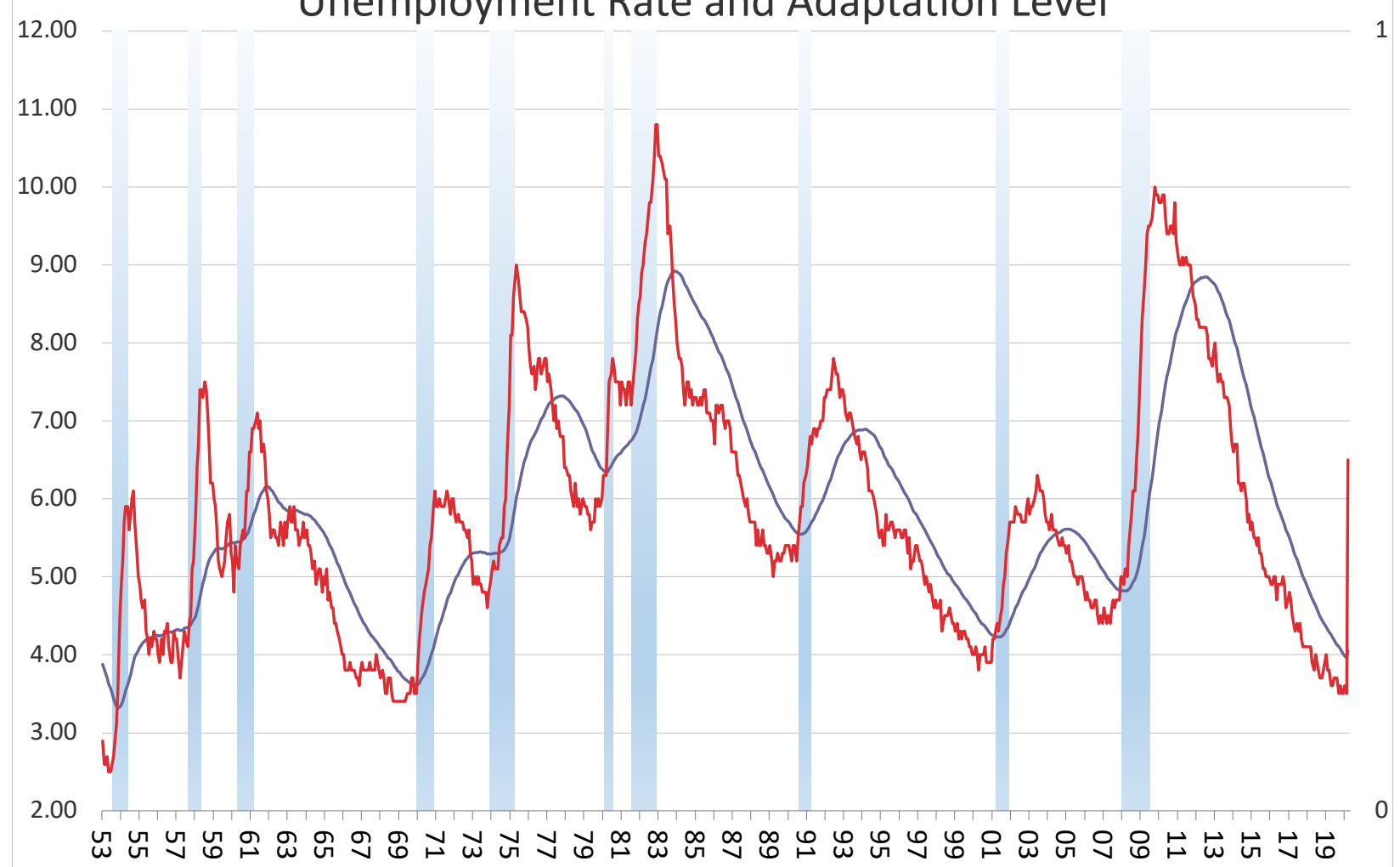

Figure 1. Unemployment rate and adaptation level

Recessions tend to begin when the unemployment rate crosses above the adaptation level. (I consider the 1980-1982 episode to be one big recession.) There are utility-theoretic reasons for the acceleration of unemployment upwards, and the corresponding collapse of confidence downwards, once "confidence goes negative." Confidence is given by the amount the adaptation level exceeds actual unemployment rate, the degree to which "things are better now." Figure 2 shows the "animal spirits" metric, with the same assumed 6.5 unemployment rate for March 2020. 


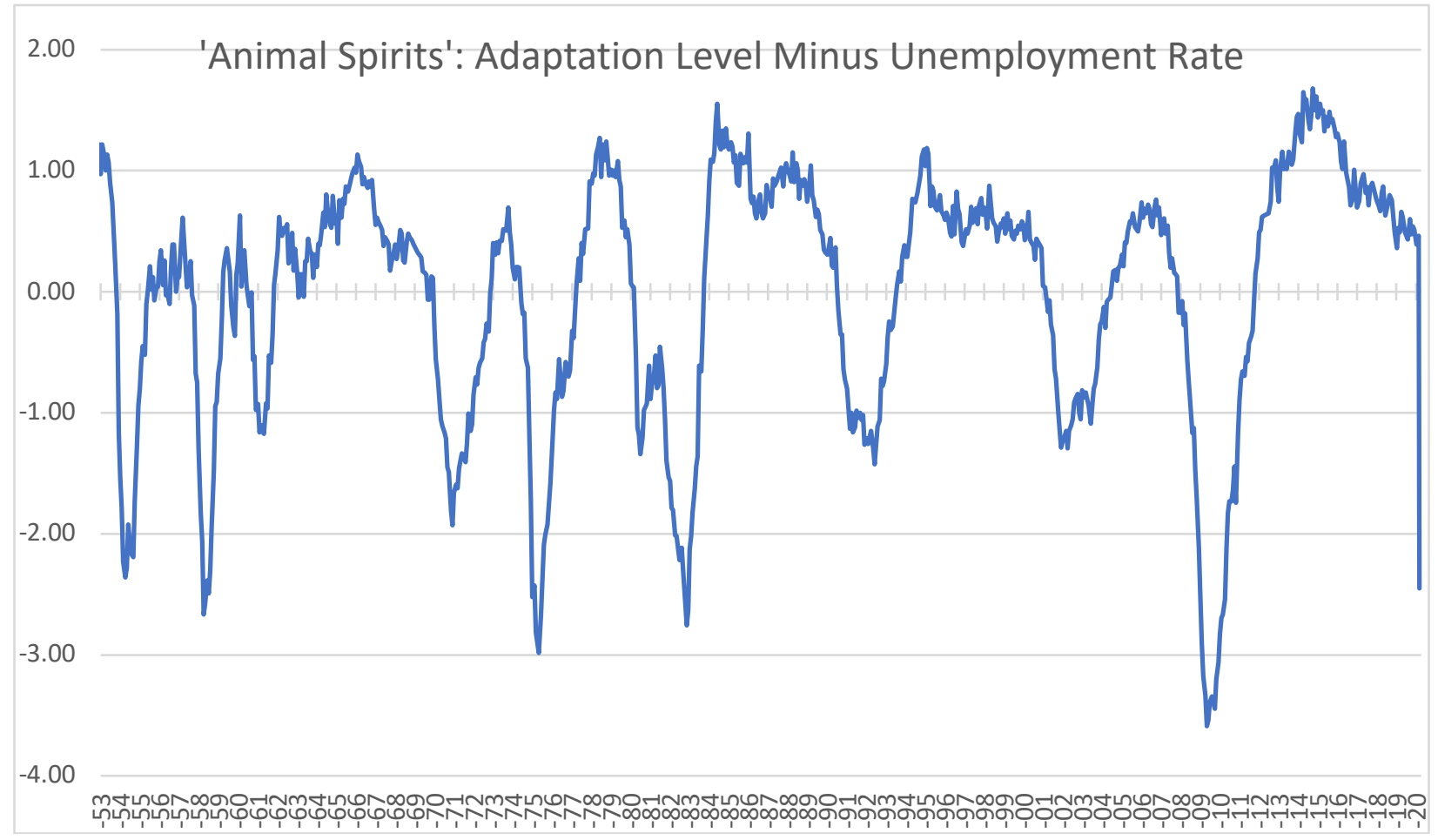

Figure 2. 'Animal spirits' metric

After the collapse of confidence, which is fed by the asymmetric loss of confidence, considered as psychological wealth, that occurs from a fall in wealth along a utility curve that is convex from above [2]. As people make millions of consumption and investment decisions in a state of lower confidence, the effects ripple through the economy. Spending sags. Unemployment increases and the process compounds in a sort of self-organized criticality for a while.

Note that confidence does not begin to recover when the unemployment rate begins to decline, but when it drops below the adaptation level. The policy implication of this is that hiding the true unemployment rate by underreporting will not help confidence to recover. Piecemeal underreporting followed by admission of the true state of affairs will delay the recovery of confidence.

Figure 3 plots the "animal spirits" metric with the Michigan Consumer Sentiment series for comparison, showing a fairly high degree of correlation. 


\section{'Animal Spirits' Metric and Consumer Sentiment}

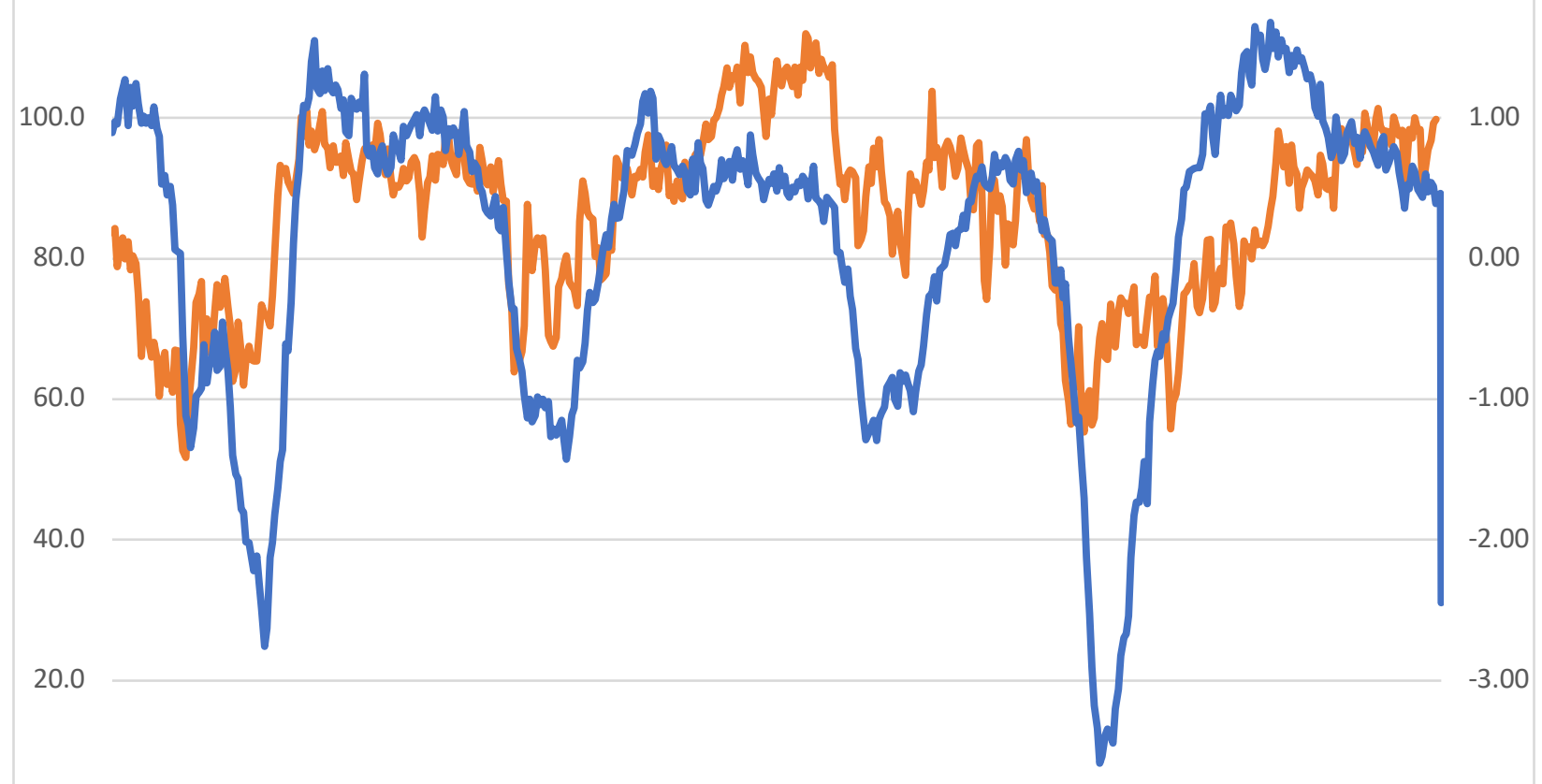

0.0

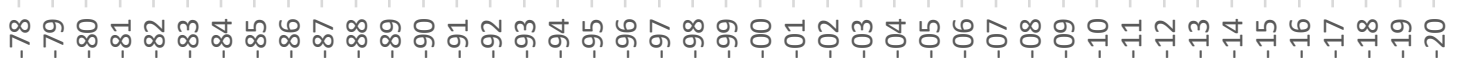

\section{Figure 3. 'Animal spirits' metric (blue) and Consumer Sentiment}

Because in February 2020 unemployment in the US was at record lows, with the adaptation level less than half a point above the actual rate, it was forecastable that the economy would experience a collapse fairly soon. As this situation also corresponds with generational low levels of trust in the government, I also forecast "a coming test of social trust in America" in an article published in 2017 [3]. SARS-cov-2 has accelerated this collapse, economically; one can hope that fighting a common enemy, the virus, will forge a new type of resolve and confidence in the breach.

However, there is a widespread belief in financial circles that the risks in the financial system have gotten worse since the last crisis, which engendered minimal or no actual reform; we have hugely increased concentration in many areas, including banking; obscene inequality of incomes and wealth; and the depositing of a Mount Everest of bad debt upon the US and the rest of the world economy. The economic collapse was eminently forecastable.

Finally, aside from the obvious point that business cycles are inevitable, given that people tend to overshoot in confidence on the upswing, and overshoot in despair on the downside, I also addressed another hallmark finding of the adaptation level literature. I began my quest into economic psychology well before it was fashionable, by reading Tibor Scitovsky's The Joyless Economy [4], which spun some insights on the boredom of mass production. Scitovsky, an 
economist, as I am, went back to the foundations of psychology in order to bring some realism to utility theory. The Wundt Curve was originally posited as a response of arousal levels and their pleasantness to subjective novelty; that is, how "new" something is relative to our experience (Figure 4). There is a vast literature in psychology and marketing on the response to subjective novelty.

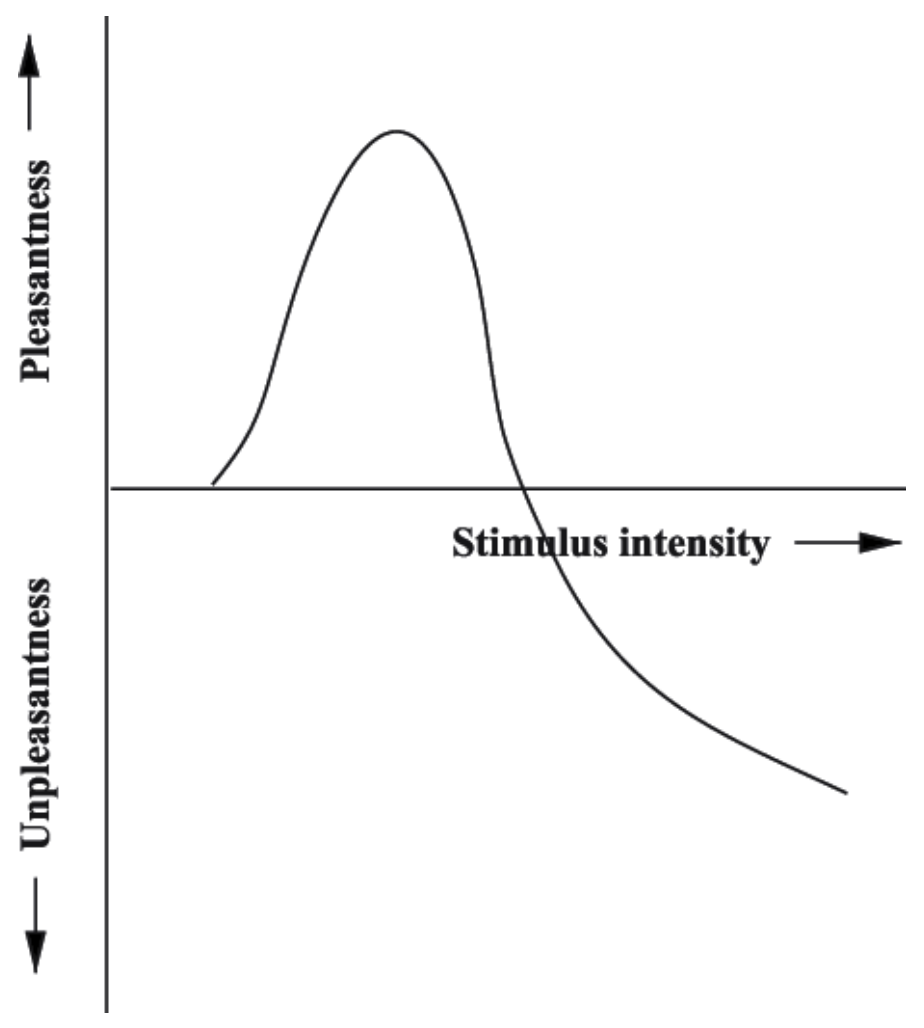

Figure 4. The Wundt Curve: Competence peaks at higher levels than pleasantness

Arousal varies directly with stimulus intensity. The classic results on the Wundt Curve are as follows: 1. Pleasantness rises to a maximum and declines into unpleasantness after a point; and 2. A measure of competence on a task associated with this stimulus follows a similar curve, but shifted to the right. It is when we are beyond the most pleasant levels of arousal that we do best. We need to be challenged, and slightly uncomfortable relative to the maximum, to achieve best performance.

I was writing during the tenure of Alan Greenspan, who ran the Fed from 1987 to 2006, and to whom the idea of any discomfort whatsoever to the financial markets was anathema. It became clear to me and many others that the infinitely accommodative monetary environment that Greenspan was creating was going to prevent necessary adjustments in all markets, distorting interest rates, wages, and asset prices grotesquely. Bernanke and Yellen followed in the Greenspan tradition, as has the current chair without having much choice in the event of a global pandemic. See [5] for more discussion of recent monetary policy. 
By reducing volatility and attempting to avoid recessions entirely, the Fed has damaged our ability to adapt to new challenges. Before leaving academia, I conceived of a macroeconomic policy based upon support for impacted workers, while allowing reasonably competitive markets to clear before excesses built up, ideally.

I conclude simply by reiterating the recommendation not to understate the true unemployment numbers going forward. Follow the existing procedures and report the results. The sooner America and the rest of the world adapt to the new reality, the sooner things can get better, both perceptually and economically.

\section{References}

[1] Middleton, Elliott (1996). “Adaptation Level and 'Animal Spirits'. JEconPsych (1996) 17:4, 479-498 https://www.sciencedirect.com/science/article/abs/pii/0167487096000207 accessed March 25, 2020

[2] Kahneman, Daniel; Tversky, Amos (1979). "Prospect Theory: An Analysis of Decision under Risk" (PDF). Econometrica. 47 (2): 263-291. CiteSeerX 10.1.1.407.1910. doi:10.2307/1914185. ISSN 0012-9682. JSTOR 1914185. from Wikipedia accessed March 25, 2020.

[3] Middleton, Elliott (2017). "The Coming Test of Social Trust in America." https://arxiv.org/abs/1708.06737 accessed March 25, 2020

[4] Scitovsky, Tibor. The Joyless Economy. New York: Oxford, 1976.

[5] Middleton, Elliott (2018) "A Partial Equilibrium Analysis of Current Monetary Policy." https://osf.io/preprints/socarxiv/ve3uw/ accessed March 25, 2020 